\title{
The Value of Mass-Produced Covid-19 Scenarios: An Evaluation of the Quality of Development Processes and Scenario Content
}

\author{
Megan M. Crawford ${ }^{\mathrm{a}}$ and George Wright ${ }^{\mathrm{b}}$ \\ aEdinburgh Napier University, 219 Colinton Rd, Edinburgh EH14 1DJ, UK \\ bStrathclyde Business School, 199 Cathedral St., Glasgow G1 1XQ, UK
}

\begin{abstract}
Hundreds of scenarios were developed across the world in the first six months of 2020, aimed at generating forward-looking conversations, better understanding COVID-19 transmission rates, trialling economic outcomes, and stress-testing existing systems in light of the developing pandemic. In response, Cairns \& Wright (2020) offer three propositions that question the value of scenarios created retroactively to existing crises. We use a distilled version of the CSI typology (Crawford, 2019) as a guiding map against which we plot each scenario's profile and test the three propositions. Our analyses largely support Cairns \& Wright's initial propositions that early COVID-19 scenarios i) are frozen pictures in time, ii) take a global perspective, and iii) are delivered to a general audience, resulting in lost value for their intended audiences and affected communities. Together, our papers develop and reinforce the message that scenario audiences should make an evaluation of all presented scenario sets using the yardsticks of (i) quality process and (ii) quality content - in order to appreciate the value of practitioner offerings.
\end{abstract}

\section{Keywords}

scenario planning, covid-19, value, disruption, future, typology, process, content

\section{Highlights}

- We developed a large database of global COVID-19 scenarios from the first wave.

- Scenarios are profiled using a comprehensive typology.

- Dimensions of scenario process and content reveal novel ways to value scenario planning.

- A yardstick against which future methods can be measured is provided.

Corresponding author: Megan M. Crawford, $\underline{\text { m.crawford@ @apier.ac.uk }}$

\section{Author's Credit}

- Megan M Crawford: Conceptualization, Methodology, Validation, Formal analysis, Investigation, Data Curation, Visualization, Writing - Original Draft;

- George Wright: Conceptualization, Validation, Resources, Data Curation, Writing Review \& Editing, Supervision 


\section{Introduction}

Cairns \& Wright (2020) reflect on the fast-paced accumulation of scenarios generated in response to the 2020 COVID-19 pandemic. One conclusion they reach is that such "quicklyproduced scenarios are not embedded in the realities of affected communities" (p 1). Others have also reflected on similar issues, bringing into question the value of scenarios created retroactively, in response to existing crises (Inayatullah, 2009; Millett, 2003). In this paper, we evaluate a collection of scenarios created during the first six months of the 2020 COVID19 pandemic. We take a closer look at the quality of both their scenario development processes and their scenario content.

\section{Defining the issue}

Three propositions are developed in Cairns \& Wright's (2020) paper, with respect to thenburgeoning corpus of COVID-19 scenario sets. First, that these scenarios are largely artefacts reflecting the realities of the time. They are, in essence, frozen pictures of the practitioners' then-knowns and then-unknowns and fail to engage, instead, an "ongoing refinement and adaptation of perspectives on the future" (p 2). Molitor (2009, p. 81) goes so far as to claim that such reactive scenario developments "merely reinforce what participants already basically knew," concluding that the effort is little more than a parlour game.

Second, Cairns and Wright propose that the scenarios take a global perspective. Further, that the scenarios tend to be entirely "good", "bad" or "neutral" throughout; failing to incorporate information that is valuable at the local level of governments or communities.

Third, Cairns and Wright propose that the mode of scenario delivery is to a general audience, failing to either engage or address the subtleties of particular affected communities. The developed scenario sets lack the flexibility to illustrate and understand the impact of plausible local actions in response to unfolding events. Specifically, self-interested actions of the powerful, such as governmental actions and directives to promote social isolation, i.e., lockdown and social distancing, are omitted from scenario storylines and citizens' reactions to these directives are also missed. If the Cairns and Wright's concerns reflect the reality of the early 2020 scenario process, then the result has been a large, expensive effort by external agents that fails to deliver any measurable impact for aiding communities that are at their most vulnerable and unstable within unfolding COVID-19-related events.

\section{Research question and aims}

Overall, our main research question asks whether quickly-produced COVID-19 scenarios provided value to the affected communities for which they were developed. The aims are to i) evaluate the potential value of early COVID-19 scenarios for their intended audiences and ii) provide guidance for future scenario planning in times of great disruption. We propose to achieve the first aim by developing the profiles of COVID-19 scenarios produced within the first six months of 2020 (i.e., "the first wave"), then use features of their profiles to compare against Cairns \& Wright's (2020) three propositions - to help determine the value of 
particular scenario sets to the target communities and organisations. Based on our discoveries, we offer guidance for improvements in the quality of future scenario planning efforts.

\section{CSI framework}

The Comprehensive Scenario Intervention (CSI) typology is used to guide our review and categorization process (Crawford, 2019). The CSI typology is divided into four overarching thematic sections which map the main focus of our efforts in the paper - project goals, process design, scenario content, and scenario impact. Each section of the CSI typology is divided into levels of sub-sections, creating over 100 possible dimensions by which to categorize a single scenario. Based on our research question and the aims of the paper, we focus on a distilled version of the CSI typology as a guiding map against which we plot each extant scenario's profile.

\section{Proposition 1: Frozen pictures}

To address the first issue - scenarios are frozen pictures - we look at the CSI typological dimensions of the practitioners involved in the process, future horizons, and temporal nature. Along with these dimensions, we included a fourth, which is whether the scenarios were revisited by the authors for updating.

Who created the scenarios? A concern is that scenarios are developed by "external agents who are not embedded in or acculturated to the communities that are the subject" (Cairns \& Wright, 2020, p. 2) The CSI typology recognizes seven common types of agents that can participate in scenario planning. An external agent can be considered an "expert", such as an industry expert, in the typological dimensions. If not an expert, participating agents can also be facilitators, problem owners, employees, stakeholders, community, and cross-populations. Facilitators are often scenario experts who guide the process and keep the project on track. Sometimes they may participate in the process, but largely serve as experienced guides or agents. Problem owners are those who hold responsibility for the outcome of the intervention. Employees, stakeholders, and community members are all sourced locally, whether from within the target organization or affected region.

Developing a horizon asks the question, How far into the future is the scenario endpoint, or time-horizon, set? Global perspectives can fall along any number of timelines. Some remark, however, that the farther away the time-horizon is set, the more general a scenario will become, as a result of this uncertainty (Schnaars, 1987; Zentner, 1975). All the same, there is no necessary association between a specific time-horizon and the specific storyline in a scenario. Short-term horizons look no farther than five years into the future; Medium-term horizons focus between five to 10 years; Long-term horizons take a long-range view that spans more than 10 years into the future. It is also the case that some scenarios develop "congruent" horizons within the developed narrative. Congruent scenario horizons present a combination of overlapping horizons (i.e. short + medium-term, short + long-term, medium + long-term, or all time horizons together). 
Within a particular time-horizon, the treatment/understanding of unfolding events that lead to the scenario out-turn may be detailed or cursory. Snapshot scenarios present a detailed view of a scenario outcome at a single point in time (Biggs et al., 2007; Godet and Roubelat, 1996). Chain scenarios present a continuous storyline that illustrates developing relationships between events in the scenario storyline as the plausible future unfolds. Varied scenarios present a zoom-in-and-out effort, where snapshots offer in-depth attention to an evolving future at a particular point-in-time, as a scenario continues to unfold.

To help provide an evidential basis for the proposition that COVID-19 scenarios are typically frozen pictures in time, we also looked at whether authors revisited their previously published scenarios to update them, redraft them, or add to a growing repository of scenarios.

\section{Proposition 2: Global perspectives}

To address the second issue - scenarios take a global perspective - we look at the CSI typological dimensions of theme, their application, the normative values they reflect, and the number of different scenarios produced in a single publication.

Arguably the most salient factor for all scenarios is the theme. What future images emerge from the process? Building from Dator's (2009) four archetypes, the CSI typology offers five overarching themes. Continued Growth (i.e continuation) scenarios project futures that build on the idea of a growing economy, society, technological advances, and other structural systems. Collapse scenarios envision a future that eventually leads to some form of integral collapse of one or several systems. The past and present serve as starting points for both of these trends. Disciplined scenarios reflect a future where some form of trend is unsustainable or undesirable, which threatens desired values or processes. These futures envision efforts that refocus and become disciplined around preserving and/or restoring previous desirable elements of our social, economic, and political lives. Dator's final archetype, Transformation scenarios, tell of some form of technological transformation that significantly redesigns or redevelops existing norms. Dator (2009, p. 10) suggests these future narratives reflect, "transformation of all life, including humanity from its present form into a new 'posthuman' form, on an entirely artificial Earth, as part of the extension of intelligent life from Earth into the solar system and eventually beyond". In addition to Dator's original four, is the CSI typological theme of Wild Card scenarios. "These are images of the future which go beyond the known knowns (predetermineds) and known unknowns (critical uncertainties), and attempt to grapple with the true nature of disruptions by reaching towards the unknown unknowns and introduce novelties" (Crawford, 2019, p. 15). Wild Card scenarios push the boundaries towards paradigmatic shifts in language, society, culture, technology, and commerce. An often-overlooked caveat of Dator's, is that the themes are neither inherently good nor bad. Continued Growth, for example, may represent the rise of an existing dictatorship as much as an increase in economic prosperity, depending on the context of the envisioned future. Equally, Collapse scenarios could represent the fall an oppressive oligarchy or terrorist organisation. The themes are generic in a sense that scenarios within a 
theme share a common theoretical, methodological, or ethical base that distinguishes them from the other themes, regardless of their specific variations.

The main concern for our COVID-19 scenarios evaluation is the prevalence of global perspectives. The CSI typology allows us to explore this feature, in part, through the application characteristic. How will the organisation want to apply the outcomes of the intervention? Generally speaking, this is a project goal determined before the scenario development process begins, which guides the process. Scenarios developed for general use are considered generic. Generic scenarios can inform subsequent, more focused and specific analysis of the implications for particular sectors or organisations. The other type of scenarios are specific in focus by initial design, e.g., contextual developments that will affect a particular industry sector, such as hospitality or tourism.

To help understand if particular COVID-19 scenarios are addressed to general audiences, we look at the intent behind the process. Normative scenarios, focus on desired futures and, as such, represent the concerns, interests, motivations, desires and occupations of the practitioners or their intended audience (van de Riet et al., 2008). These scenarios can include prospective, strategy, policy and intervention scenarios (van Notten et al., 2003). By contrast, descriptive scenarios present plausible or hypothetical futures with little to no accounting for the level of desirability of those outcomes When scenarios incorporate descriptive hypothetical futures with normative desires in equal measure, they are profiled as reflecting a dynamic narrative.

A final measure of perspective in scenarios, is the quantity of different scenarios each organisation developed around various COVID-19 futures. As we shall see, some organisations develop a single scenario, reflecting a single theme, some develop scenarios that permutate 'good vs bad' themes, and some organisations develop a broad selection of niche scenarios. In a minority of cases, organisations revisit their scenarios to update them, as new information becomes available.

\section{Proposition 3: General audiences}

To address the third issue, scenario audience, we look at the CSI typological dimensions of the nature of the information utilized and reflected in the scenarios, and the role of the decision makers in the scenario development process.

Information utilised in the scenario development process can be either quantitative (e.g. percentage changes in projected GDP) or qualitative in nature (e.g. intuitive interpretations of the impacts between driving forces). Information can be gathered through a number of methods or a combination of several methods. Participatory methods are active and include interactive sessions with other practitioners, often group-based. Sessions can include interviews, brainstorming sessions, think-tanks, group discussions, surveys, workshops, Delphi-style ranking scores, incasting, role playing, storytelling, intuitive logic, visioning, and/or focus groups (Bishop et al., 2007; Dator, 2009; de Vasconcelos et al., 2012; Grevi et 
al., 2013; Teufel et al., 2013; van de Riet et al., 2008). Desk research, on the other hand, is a passive method, that can include literature research, data mining, clustering, and computer simulations, and modelling (Allington et al., 2018; Johnson and Sieber, 2011; Van Notten et al., 2003). As well, any combination of information or data collection can be employed for a single scenario planning effort.

Finally, to gain insight into the type of audience for which particular COVID-19 scenarios were intended, it is important to know whether "decision makers" participated in the scenario development process. Participants may be, simply, general practitioners or organisational/sectoral members/representatives, or a collaboration of representatives from both groups that involves the scenario practitioners consulting with industry experts, but not necessarily including them in the scenario planning process (Crawford, 2019).

\section{Method}

We utilized a mixed-method analysis using transformed qualitative data in order to gain a richer understanding of each scenario analysed. To begin, a framework of dimensions was developed from a distilled version of the CSI typology. Proposition 1, Frozen Pictures, encompasses the dimensions of practitioners, time horizon, temporal nature, and scenario revision. Proposition 2, Global Perspectives, encompasses archetypal themes, scenario application, value/reality, and quantity dimensions. Proposition 3, General Audiences, encompasses the dimensions of information collected, information presented, and involvement of decision makers.

While building each scenario's profile, four dimensions were added alongside the CSI typology, to help fully address Cairns \& Wright's (2020) original propositions. The first dimension expands the practitioner characteristic with the category Arm's length, which encompasses consulting professionals, journalists, and scenario authors who did not fit within the other categories. We designated this group Arm's length because these authors worked independently of the organisations and stakeholders targeted by their scenarios, were not identified as experts in the industries, fields, or sectors their scenarios encompassed, nor were they scenario experts facilitating a workshop or intervention. The second dimension applies to proposition 1 by identifying publishers who Revisited their previously published scenarios. The final two additions are sub-categorical dimensions of Dator's Continued Growth theme within proposition 2. After text and theme classification, subtle yet measurable differences between the different Continued Growth scenarios began to emerge. Our process and justification for branching the Continued Growth theme are explained further in the Scenario profile curation section.

Table 1 presents the framework of dimensions used to develop each scenario's profile, which is a distilled version of the fuller CSI typology. In the case of themes, levels of subcategorical dimensions are offered to distinguish between important nuances of each category's meaning. Overall, our framework allows for an 11-point profile to be developed for the development and content of each scenario analysed. 
Table 1. Framework of profile dimensions

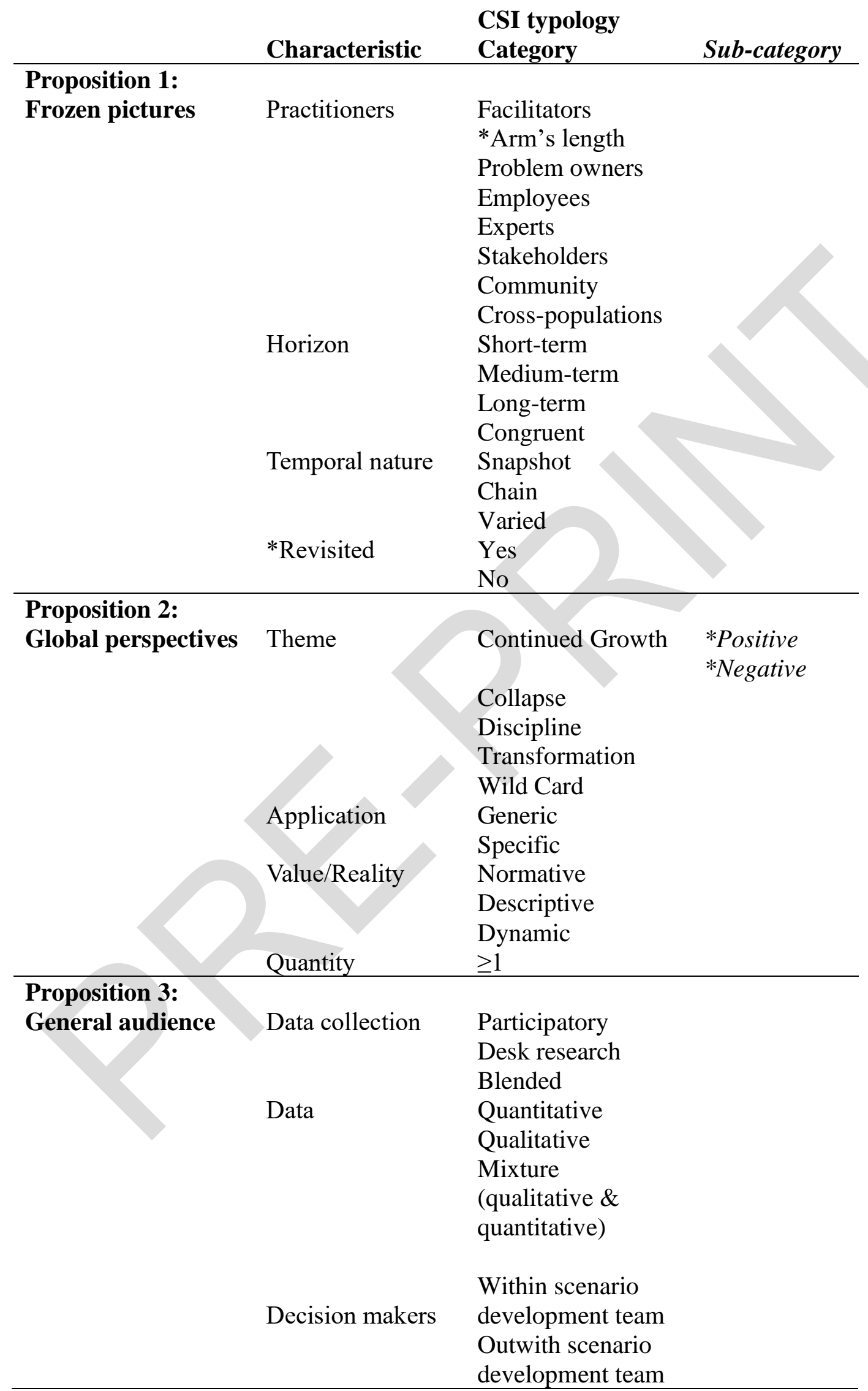


Note: We replaced the Data category "Complimenting" from the original CSI typology with the label "Mixture of qualitative and quantitative" to relay the meaning behind our analyses more clearly.

\section{Search criteria}

Our goal was the locate as many scenarios as possible within the available timeframe. The search effort took place between May and August 2020. Initially, the criteria for date range of COVID-19 scenario publications was set at January - June 2020. However, this date range was later expanded, making a second criteria for date range to allow for related scenarios published earlier than January 2020, i.e., before the current COVID outbreak. Our initial and secondary searches resulted in the identification of 181 publications which contained scenarios.

COVID-19 scenarios were first sourced from an existing repository of scenarios, as part of a then on-going data collection activity at Strathclyde Business School. In conjunction with the repository, we conducted searches using Google, government sources, contacting public and private organisations, and other existing connections previously established with the research team (that resulted in a few scenarios being emailed directly to the team). For online searches, the terms "scenario" or "scenario planning" were crossed with "covid", "covid19", "covid-19", "covid 19", "coronavirus", "pandemic", and/or "health crisis". Results were initially collected without curation. Scenarios published prior to January 2020 located through our second criteria included any combination of the search terms "coronavirus", "pandemic", "health crisis", and "2020", along with any the scenario search terms.

During the search phase, we discovered that some publicly accessible scenarios online (and their related information) had been replaced with updated scenarios and current COVID-19 information in a way that appeared to delete prior published work. To increase the chances that we accessed any potential past and present COVID-19 scenarios from the same sources, we emailed authors, as well as used the Internet Archive, a constantly updated digital library of internet sites and other cultural artifacts in digital form, by use of the Wayback Machine (1996).

\section{Scenario profile curation}

The first round of curation selected original scenarios, including those secondary sources that reported others' original scenarios. We started with Spaniol \& Rowland's (2018) definition of a scenario to separate publications that included scenarios from those that included scenario-like content, but were otherwise not scenarios. The authors provide a summary table and diagnostic flowchart to be used individually or together as diagnostic tools to identify scenarios. Their criteria for a text to be a scenario are i) future oriented, ii) reference external forces, iii) a narrative description, iv) possible and plausible, v) a systematized set, and vi) comparatively different. 
The non-scenarios included such publications as articles that speculated on future necessities, promotional materials, and pure modelling forecasts absent of narratives. ${ }^{1}$ Duplicates were also removed. First-round curation reduced the dataset to 44 unique publications from 42 organisations that produced a total of 216 scenarios. In the case of the Economist Intelligence Unit (EIU: The Economist Intelligence Unit, 2020), each scenario in a single month's release was published with a unique URL and not explicitly linked with the other scenarios published in the same month. However, we profiled their scenarios as a systematized set because they provided a summary table of Global assumptions and a summary list of key changes for the month's collection of scenarios. The rest of our sourced organisations published all their scenarios from a single session into one publication.

The second round of curation applied and developed our 11-point profile for each scenario. As discussed, COVID-19 scenario profiles were constructed from the selection of CSI typological categories that best described the scenario content. Each scenario profile reflected only one indicative major categorical dimension, even though it was sometimes possible for some scenarios to cross several categories.

Some CSI characteristics have mutually exclusive categories. Scenarios were either revisited by their authors, or not. This was determined through a variety of methods, including emailing the authors, online searches with date changes, and use of the Wayback Machine (1996). We also attempted count the number of revisions. This was only pursued for organisations that were confirmed to have revised or revisited their earlier COVID-19 scenarios. The quantity of scenarios produced in a single publication was profiled with a single integer. A scenario's application was either aimed towards a general audience or was designed for a specific sector or organisation. Scenario content was either highly elaborative - sharing both qualitative and quantitative data, or verbose - or presented a simple narrative. The target audience's decision makers either participated in scenario planning or they did not. The theme of a scenario, however, proved to be a little different. As Dator (2009) recognised, some scenarios may reflect several themes, different paths for different target audiences highlighted within the scenario. This proved to be potentially true for the longer, more complex scenarios. However, after reiterative reviews, our sample proved to reflect Dator's experience that even though futures may seem to overlap between more than one theme, most fall "very naturally into one of the four-and no more" (p. 6).

\footnotetext{
${ }^{1}$ A selection of false hit examples from our search criteria are offered for illustration. Oliver Wyman consulting firm created the Alternative What-if Scenario Modeling, as part of their COVID-19 almanac (accessed June 2020, https://pandemicnavigator.oliverwyman.com). They offer simple graphical projections of growth rates up to 3 weeks in the future. The UN published Be Ready for COVID-19: Key Scenarios flyer to advise on following specific behaviours under the scenarios of meeting others, travelling, and staying home (accessed June 2020, https://www.who.int/emergencies/diseases/novel-coronavirus-2019). Iberdrola electric utility company published a shareholder's bulletin for Q1 of 2020 that focused on their recovery from the crisis created by COVID-19. They only mention their financial resiliency against a "stress scenario" (accessed June 2020, p. 5, http://www.iberdrola.com). The New York Magazine reported early estimates from the CDC of the virus' projection "if no action was taken to slow the spread", and referred to this as a scenario (13 March, 2020, https://nymag.com/intelligencer/2020/03/cdcs-worst-case-coronavirus-model-210m-infected-1-7m-dead.html).
} 
The remaining characteristics have the potential for overlapping categories. The CSI typology accounts for such multiplicity by offering a final heterogeneous category for these dimensions. Practitioners can represent any combination of the six separate homogeneous groups who could have participated in developing the scenarios. When practitioners from more than one homogeneous group developed COVID-19 scenarios together, the scenario profile assumed a cross-population dimension. The future horizon set for each scenario could be short-, medium-, or long-term, however some scenarios presented rolling storylines with multiple milestones highlighted along two or more horizon categories. These scenarios were profiled with a congruent horizon. For example, a short-term scenario presents a horizon that is anywhere withing five years, however, a congruent horizon could present the same shortterm horizon and expand it further into a medium-term future, reaching as far as 10 years. When a scenario presented a zoom-in-and-out effort, where causally linked developments of events were occasionally paused along the timeline to serve as checks or moments of focused development in the storyline, it was categorised as having a varied temporal nature. The level of desirability reflected in the value and reality of each scenario could be primarily hypothetical, which illustrated descriptive story telling elements, or normative, the latter representing a value-focus, guided by the concerns and interests of the practitioners. Many scenario scholars agree that it may be impossible to create scenarios totally void of normative elements, even if at the implicit level (Ducot \& Lubben, 1980; Glenn \& Gordon, 2000; Heugens \& van Oosterhout, 2001). Scenarios that reflected both descriptive and normative elements, were categorised as having dynamic value/realities. Scenarios with data collected through both isolated desk research methods and group participatory engagement were categorised as having a blended effort in development.

Following Grimmer \& Stewart's (2013) text data classification method, we began with a supervised method of individual classification. "Human hand coding" (p. 269) of words and phrases that came from the first round of classification led to the development of an ad-hoc dictionary for each CSI category and sub-category. The growing dictionary helped guide ongoing classifications of COVID-19 scenarios, as well as served to check for any disputes between coders.

To help with theme categorisation, we first adopted Fergnani \& Jackson's (2019) scenario archetypes dictionary for Continued Growth, Collapse, Discipline, and Transformation. However, we quickly discovered a translation issue across Continued Growth and Collapse scenarios. In isolation, words from their Continued Growth dictionary reflected both positive and negative Continued Growth, as well as some Collapse scenarios. The same was true of several words from the Collapse dictionary appearing with varying frequencies in differently framed Growth scenarios. This is not a criticism of Fergnani \& Jackson's scenario archetypes dictionary. In fact, we feel the authors developed a helpful heuristic for thematic categorisation. Rather, interestingly enough, it appears that perhaps the language used to describe plausible COVID-19 futures may have been applied in contextually different ways from how the same language was used in workforce/workplace futures, pre-pandemic (the focus of Fergnani \& Jackson's dataset). It is also important to note that Fergnani \& Jackson's dataset was built from sources other than scenarios, which may have further introduced non- 
applicable contextual variations. Therefore, the third round of curation re-analysed our thematic profiling by adopting the same human hand coding efforts as the other profiled categories. This effort divided the original CSI typological dimensions of Continued Growth and Collapse scenarios across three descrete scenarios: Positive Continued Growth, Negative Continued Growth, and Collapse. One result of this new division was the recognition that Negative Continued Growth scenarios, thematically, had more in common with Collapse scenarios than Positive Continued Growth scenarios.

Early in the process of categorising the Practitioner dimension, scenario data revealed a need for further elaboration, similar to the explicit thematic elaboration of Positive/Negative Continued Growth. In the original CSI typology, the Facilitators category included scenario experts and consulting professionals (Crawford, 2019). The unique blend of the practitioners who contributed to our dataset of COVID-19 scenarios required a more nuanced recognition of facilitator identity. For example, the three scenarios developed for the Atlantic Council's "Foresight, Strategy, and Risks Initiative" were authored by facilitators to the scenario sessions, however there were no other consultants (Burrows \& Engelke, 2020, April). In comparison, Kantar's Health Division developed three scenarios for the US healthcare landscape with their team of professional consultants and industry experts, but did not indicate that facilitation took place at any stage in the process (Kantar, 2020, June). Finally, the Wood Mackenzie group developed three scenarios, centred around energy and natural resources, with a team of professional consultants who were not associated with the communities and organisations their work was meant to target (McKinsey \& Company, 2020, May). We consider this last group of scenarios to be the product of consultants working at arm's length of the target audiences. An updated division of practitioner identities was determined necessary for addressing Cairns \& Wright's (2020) first proposition. Unlike the uni-dimension of thematic categories, there could be any number of practitioners from the different homogeneous groups that participate in scenario development activities. Therefore, rather than further sub-categorise Facilitators, we added a new category to the Practitioners dimension, Arm's length (e.g. consulting professionals). In this way, we leave the door open for the possibility that a COVID-19 scenario planning workshop was facilitated with a group composition that included consulting professionals but no industry or community representatives. If this were the case, then their resulting scenario profiles would be categorised as having been developed by a cross-population of practitioners.

The fourth and final round of curation served as a validation check. To increase the validation of categorising by hand, both authors independently profiled a larger sample of COVID-19 scenarios. Once completed, scenario profiles were compared for coding differences. All differences were due to one of two issues: 1) a simple entry/reading error on the part of the researcher or 2) a difference in interpretation of the scenario's content. The first issue was quickly corrected. The second issue required further review of the scenario and agreement by the authors. Less than $10 \%$ of coding differences were due to interpretative differences. 


\section{Results}

\section{Proposition 1: Frozen pictures}

The first set of analyses looks at who developed the scenarios, what kind of future horizon they set for their scenarios, the temporal nature of the story-telling, and whether practitioners revisited their original scenarios. Figure 1 illustrates the percentages of practitioners involved in scenario planning. The largest percentage of scenarios (77.4\%) were developed exclusively at arm's length. A chi-square goodness of fit test shows a significant difference between the proportions of practitioner-backed scenarios, $\chi^{2}(3, n=216)=319.04, p<.000$, supporting the results that a large majority were developed by arm's length practitioners, followed by heterogeneous cross-population groups of practitioners, then exclusively experts (just one expert in the case of Honey, 2020, April; Kesson, 2020, April; Palma, 2020) and the smallest proportion developed by lone facilitators. No scenarios were developed exclusively by community members nor problem owners. If we take into consideration that scenarios developed by a cross-population of different homogeneous groups of practitioners all included consultants at some point in scenario planning, then it is revealed that outside consultants were the main source for COVID-19 scenarios in the first half of 2020 (89.8\%).

\section{Figure 1. Practitioners who developed COVID-19 scenarios}

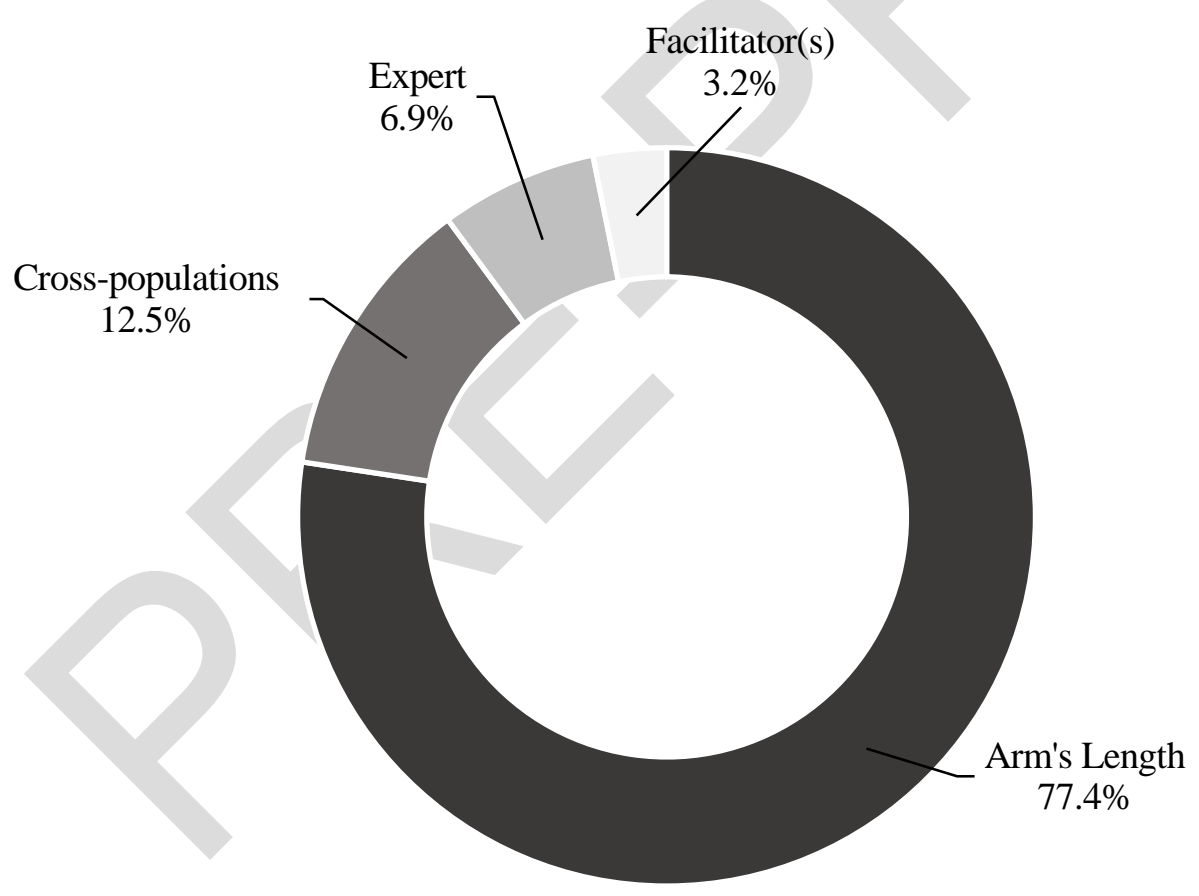

COVID-19 scenarios significantly favoured short-term time horizons (78.7\%), with the next popular being long-term (7.4\%), followed by medium-term $(4.6 \%)$, and finally the least common horizon presented were congruent ones (1.8\%). An example of a congruent horizon scenario was provided by EIU. In their scenario, The Global Economic Recovery Will 
Be Slow, the years under reflection moved from a short-term horizon (2020-2024) to a medium-term horizon (2025-2009) (The Economist Intelligence Unit, 2020).

The coronavirus (Covid-19) pandemic is a game-changer for the global economy; 2020 and 2021 will be lost years in terms of growth. The Economist Intelligence Unit only expects the global economy to recover to pre-coronavirus levels in 2022. China is an outlier, as its GDP will not contract this year. Other Asian economies will recover the fastest, with some (including India and South Korea) returning to pre-coronavirus real GDP levels in 2021. G7 economies will recover more slowly. GDP will be back to 2019 levels in 2022 (Canada, Germany, the US), 2023 (the UK) or 2024 (France, Italy). Japan will be an outlier among G7 countries, with real GDP only returning to prepandemic level sin 2026. (emphasis added)

The distribution of featured horizons significantly favor scenarios set less than five years into the future, $\chi^{2}(4, n=216)=467.52, p<.000$. Surprisingly, $7.4 \%$ of COVID-19 scenarios did not discuss a time horizon at all. Figure 2 presents the preference of temporal storylines within each horizon category. The time horizon is given in years, along the $\mathrm{x}$-axis: short-term $(<5)$, medium-term (5-10), and long-term $(>10)$. The y-axis shows the frequency distributions of how the unfolding events were relayed (i.e. temporal - varied, chain, or snapshot) within each horizon cluster. We chose to represent the data in Log scale due to the extreme skewness in snapshot scenarios. Circle size represents the percentage of temporal features distributed across all time horizon clusters. For example, the first column of the chart reports that there were 170 scenarios set less than five years into the future (short-term horizon). Within the short-term horizon cluster, the majority of scenarios presented a snapshot of a future ( $n=143)$, followed by slightly more elaborate causal chain-of-events narratives $(n=$ 24 ), and the least common form provided a narrative that relayed a chain-of-events about the future with occasional stop-gaps that elaborated more completely on a particular feature of a future, industry, or event $(n=3)$. If we look, next, at the distribution of temporal information, the charts reports that the largest percentage of snapshot scenarios were given short-term timelines $(84.6 \%)$, followed by equal representation with either a medium-term $(2.4 \%)$ or long-term horizon $(2.4 \%)$, and the smallest percentage of snapshot scenarios featured congruent timelines (1.2\%). Not reported in Figure 2 are the scenarios that presented no time horizon $(9.5 \%)$, which just happen to also be exclusively snapshot storylines.

A test for independence shows that there is a significant association between the distance of a chosen horizon (short-, medium-, long-term, or congruent) and how the temporal narrative is delivered (varied, chain, or snapshot), though with a small effect size, $\chi^{2}(8, n=216)=53.70$, $p<.000, n^{2}=.09$. Short-term scenarios were more likely to present brief snapshots of plausible COVID-19 futures, compared to the other time horizons. While medium- and longterm scenarios were more likely to present plausible futures that described chains of causal events over time. Only the extreme time horizons (short- and long-term) included efforts that took on a varied approach, with zoom-in-and-out efforts and stop-gaps. Varied scenarios 
were, understandably, more complex, not just in word count $\left(M_{\text {words }}=617.77, S D_{\text {words }}=\right.$ 18.93), but other scenario features as well (e.g. figures, predictions, and impact projections).

The nature of congruent time horizons gives the impression that, by default, scenarios would report either varied or chain temporal story elements. This was surprisingly not the case, where $50 \%$ of the scenarios offered a snapshot view of futures, and all had low complexity story elements (e.g. only qualitative data). In other words, simplistic scenarios, often only one paragraph in length $\left(M_{\text {words }}=145.54, S D_{\text {words }}=20.82\right.$; see EIU (2020) The Global Economic Recovery Will Be Slow example above, for illustration).

Figure 2. Division of temporal nature per scenario horizon

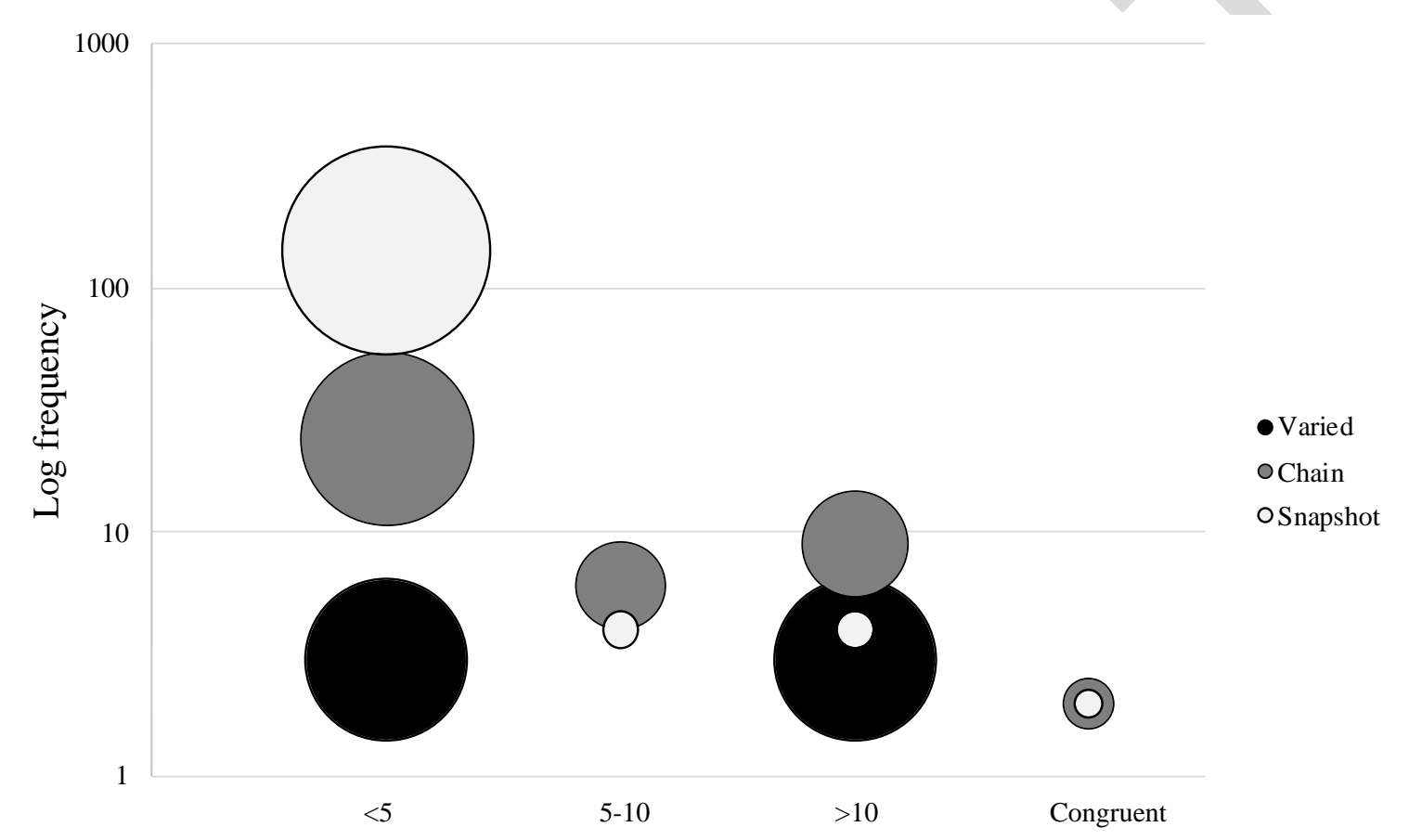

Time horizon by years

The final analysis that addresses Cairns \& Wright's (2020) first proposition is whether earlier COVID-19 scenarios were revisited by the authors. Out of 44 organisations, we identified previously-developed scenarios were revisited by five organisations:

PricewaterhouseCoopers (PWC) (Forrest, et al., 2020, June; Forrest, et al., 2020, May), The Red Team Analysis Society (Lavoix, 2020, May), Vision Foresight Strategy LLC (2020, March; April), Deloitte (Blau \& Schwartz, 2020, April; Kalish, et al., 2020, April), and Kantar Group Limited (Kantar) (Abraham, Burdett, Carbone, \& Warwick, 2020, April; Kantar, 2020, June). Content analysis reveals that authors who revisited their previous scenarios made one of two revisions. The first revision type readdressed and revised the previously published content. This includes any parts of the publication: updated world statistics, scenarios, model projections, and interpretations. The second revision type did not readdress or revise previous content but, instead, published new content. We detail these two types of revisions next. 


\section{Readdressed/revised content}

PWC updated their May report, "COVID-19 UK Economic Update", with new COVID-19 related data and published a second report in June (Forrest, et al., 2020, June; Forrest, et al., 2020, May). Their updated June report was shorter; However, the two scenarios they developed for their May report were not updated and were repeated verbatim from the earlier report.

The Red Team Analysis Society published regular updates of information as the pandemic progressed through the spring months and referenced their original early scenarios in each publications (Lavoix, 2020, May). They did not update their original four scenarios, "Worst Case Baseline Scenarios for the COVID-19 Pandemic", but rather used them to measure our unfolding reality against, moving from one to another as the world's infection and death rates increased.

Vision Foresight Strategy LLC published three scenarios in March, then revisited just their worst-case scenario, The Bad Scenario, in April (2020, March; April). Their motivation was to reconsider the "more challenging scenarios" (p. 12) in light of new and emerging indicators.

Deloitte released two separate scenario publications in April as part of their respond-recoverthrive resilient leadership framework (Blau \& Schwartz, 2020, April; Kalish, et al., 2020, April). The first three scenarios focused on economic recovery. The second group of four scenarios focused on broader implications of thriving through the pandemic not just for economic systems, but healthcare and social systems as well, integrating their narratives together in pictures of the future.

\section{New content}

Kantar published new scenario content in their revision, focused on uniquely different industries (Abraham, Burdett, Carbone, \& Warwick, 2020, April; Kantar, 2020, June). Kantar's first April publication focused on two sets of scenarios - People Point of View and Institutional Point of View - four scenarios in each set. Their June publication included four scenarios for the Healthcare Point of View, making no mention of previous content.

\section{Proposition 2: Global perspectives}

Our second set of analyses looks into the kinds of themes that practitioners explored, whether and how they developed scenarios for a general or a targeted audience, whether or not the scenario was normative or descriptive, and the quantity of scenarios produced by a single source.

Theme analysis reveals that practitioners were largely focused on imagining damaging, adverse, or detrimental plausible futures (Collapse (36.1\%) and Negative Continued Growth $(11.1 \%)$ ), as opposed to highly controlled Disciplined (32.4\%), Positive Continued Growth (9.3\%), Transformation $(11.1 \%)$, or Wild Card futures (0\%). Treating each of the five themes 
as unique variables, a chi-square goodness of fit test reveals a significant difference between the popularity of themes, $\chi^{2}(4, n=216)=74.19, p<.000$, supporting our results that COVID-19 scenarios focus more on Collapse and Disciplined futures in comparison to the other themes. The intended application of scenarios is also significantly different. A significant majority of scenarios $(67.6 \%)$ were developed with a generic application for a general audience, as supported by a chi-square test $\chi^{2}(1, n=216)=29.69, p<.000$. The value/reality division across scenarios is not significant, reflecting an equal representation of normative and descriptive elements across the collection of scenario narratives. Figure 3 illustrates the relationship between themes and their internal expressions of value/reality and application (general audience versus tailored to a specific audience). The y-axis, in the middle, is ordered from the most negative themes at the top, progressing down across themes that are categorically defined as more positive than the previous, and ending with the ambiguous theme, Transformation scenarios. To the left are the divisions of value/realities (descriptive, dynamic, and normative). To the right are the divisions of scenario application (generic and specific).

Figure 3. Theme, value/reality, and application relationships

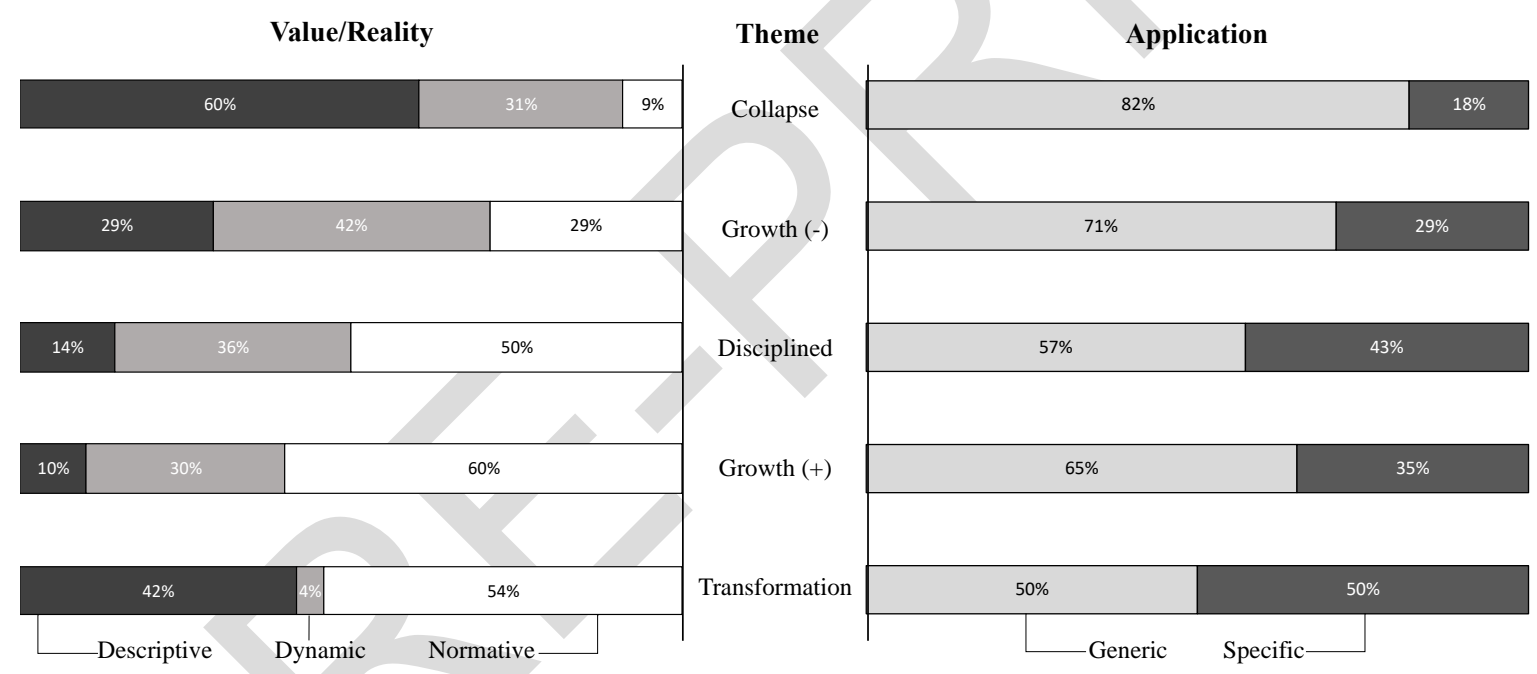

Note: Continued Growth is divided into its thematic sub-categories: Negative (Continued Growth (-)) and Positive (Continued Growth (+)). Wild Card is not represented because no COVID-19 scenarios matched this thematic description.

Taking into consideration the unambiguous first four themes, there appears to be a significant relationship with the levels of normative value within the scenarios, but with a small effect size, $\chi^{2}(6, n=197)=57.86, p<.000, \eta^{2}=.06$. Transformation scenarios are discussed separately. Collapse and Negative Growth scenarios reflected more descriptive, hypothetical pictures of the futures. More than other themes, the severely adverse or detrimental scenarios included baseline, reference, and non-interventions with COVID-19. Table 2 presents a selection of Collapse and Negative Growth scenario passages that illustrate these topics. 
Table 2. Collapse and Negative Growth baseline, reference, and non-intervention scenario passages

\begin{tabular}{|c|c|c|}
\hline Scenario & Content & Topic \\
\hline $\begin{array}{l}\text { Targeted Curriculum } \\
\text { (MOODY'S, 2020, March) }\end{array}$ & $\begin{array}{l}\text { "1 million global infections, } \\
\text { new infections peak in } \\
\text { March,1-2\% mortality rate, } \\
3-4 \% \text { hospitalization rate, } \\
\text { infections abate by June." }\end{array}$ & baseline \\
\hline $\begin{array}{l}\text { Worst Case Baseline } \\
\text { (Lavoix, 2020, May) }\end{array}$ & $\begin{array}{l}\text { "This implies having at least } \\
\text { a crude worst case baseline } \\
\text { scenario in terms of } \\
\text { fatalities. In other words, we } \\
\text { need to have an idea of what } \\
\text { would be likely to happen if } \\
\text { we were not acting." }\end{array}$ & baseline, non-intervention \\
\hline $\begin{array}{l}\text { Scenarios } A, B, C \\
\text { (Kissler, Tedijanto, } \\
\text { Goldstein, Grad, \& Lipsitch, } \\
\text { 2020, April) }\end{array}$ & $\begin{array}{l}\text { "...especially large } \\
\text { resurgences agrees with data } \\
\text { from the } 1918 \text { influenza } \\
\text { pandemic in the United } \\
\text { States, in which the size of } \\
\text { the autumn } 1918 \text { peak of } \\
\text { infection was inversely } \\
\text { associated with that of a } \\
\text { subsequent winter peak after } \\
\text { interventions were no longer } \\
\text { in place." }\end{array}$ & erence, non-intervention \\
\hline
\end{tabular}

Brief Chaos

(Abraham, Burdett,

Carbone, \& Warwick, 2020, April)

Scenario 2: Fall Peak

(Moore, Lispsitch, Barry, \&

Osterholm, 2020, April)

(Begley, 2020, May)

The Grand Depression (IARAN, 2020, June) “...especially those that

non-intervention were slow to act or unable to implement the controls necessary to contain the virus."

"This pattern is similar to reference what was seen with the 1918-19 pandemic."

"Yet there was a consensus baseline that the outbreak would not be contained."

"While most cases still do not present with severe symptoms, but no satisfactory treatment has non-intervention 
been found, and so mortality

rates spike..."

Scenario 1

(CDC, 2020, April)
"[Scenario 1 is] based on parameter values that represent the bounds of disease severity and viral transmissibility." baseline

\begin{abstract}
As scenario themes moved from the most detrimental visions of the future towards more
\end{abstract} positive visions of the future, their values appeared to change as well, adopting less explorative hypothetical content, towards more normative content with desirable narratives. It is important to note, however, that some Disciplined scenarios still painted bleak or difficult futures featuring qualities of controlled adaptations around "new norms". An example of a Disciplined theme with bleak adjustments to new norms was provided by Deloitte, in their Harsh Economic Case scenario, "Before long, virtual life is real life in many places...

Extended and severe virus leads to all things virtual as the norm... Technologies of the fourth industrial revolution accelerate in development due to greater demand... Recovery is slow in early $2022 \ldots$ Deep and prolonged recession in the West affects supply chains and consumer demand" (Kalish, et al., 2020, April, p. 6). Table 3 presents a selection of Disciplined and Positive Growth scenario passages that illustrate normative and desirable topics.

Table 3. Disciplined and Positive Growth normative and desirable scenario passages

\begin{tabular}{|c|c|c|}
\hline Scenario & Content & Topic \\
\hline $\begin{array}{l}\text { Back to Normal } \\
\text { (Maloney \& Kim, 2020, } \\
\text { April) }\end{array}$ & $\begin{array}{l}\text { "In this scenario, the fall } \\
\text { semester looks like any } \\
\text { other fall semester." }\end{array}$ & normative \\
\hline $\begin{array}{l}\text { Global Containment } \\
\text { (acaps, 2020, April) }\end{array}$ & $\begin{array}{l}\text { "Outside of [low income] } \\
\text { countries, health services } \\
\text { continue at pre-crisis } \\
\text { levels... Containment } \\
\text { measures reduce organised } \\
\text { crime activities..." }\end{array}$ & normative, desirable \\
\hline $\begin{array}{l}\text { Responding to Change, Kind } \\
\text { of } \\
\text { (Vision Foresight Strategy } \\
\text { LLC, 2020, March) }\end{array}$ & $\begin{array}{l}\text { "After the disease was } \\
\text { contained, people generally } \\
\text { had a better understanding } \\
\text { about avoiding travel during } \\
\text { disease outbreak, proper } \\
\text { methods of sanitation... } \\
\text { With each outbreak, the } \\
\text { systems in place for } \\
\text { responding to them and }\end{array}$ & desirable \\
\hline
\end{tabular}


Fight

(Candelon, et al., 2020,

April)

China is Ahead of the

Coronavirus Epidemic

Curve

(The Economist Intelligence

Unit, 2020)

In-person Learning for All Students

(Minnesota Department of Health, 2020, June)) preventing future outbreaks

improved..."

"Quickly resume business activities and ramp up"

normative, desirable

"Economies that were hit

normative, desirable

first, including China, Hong

Kong, Japan, Singapore,

South Korea and Taiwan,

managed to contain their

initial outbreaks in January

and February... Asian

economies will be the first

to recover... with many economies back to precoronavirus GDP levels in 2021."

“... schools should create as

normative

much space between

students and teachers as is

feasible during the day, but

will not be held strictly to

enforcing 6 feet of social

distancing during primary

instructional time in the

classroom."

“An early return to normal

normative, desirable
Rebound
(The Nielsen Company, 2020, May) living conditions (schools, workplaces, stores, restaurants, etc re-open) at some point in the third quarter of $2020 . "$

The same four themes also reflected a bias towards generic applications, again with the exception of Transformation scenarios. Generic scenarios focused on either global causal relationships and patterns or a broad selection of industries. Specific scenarios were developed for military (Cederquist, Gibbon, \& Lum, 2018, September), education (Ikramuddin, 2020, May; Kesson, 2020, April; Maloney \& Kim, 2020, April), energy (Crooks, et al., 2020, May; Kantar, 2020, Jun), employment (Palma, 2020), international trade (Forrest, et al., 2020, June; Forrest, et al., 2020, May), medicine (Kissler, Tedijanto, Goldstein, Grad, \& Lipsitch, 2020, April; Kuchta, Lazerow, Pratt, \& Tyrell, 2020, March; Minnesota Department of Health, 2020, June), container shipping (Drewry Shipping 
Consultants Limited, 2020), finance (Verbraken \& Sampieri, 2020), and local government (McKiernan, Wright, Thomson, \& Gupta, 2020, July).

Transformation scenarios generally explore narratives absent of a priori assumptions of 'good' and 'bad'. This ambiguity was reflected in both the proportion that shared different normative and descriptive values, as well as their application towards generic or targeted audiences.

In an effort to understand whether a change in thematic perspectives occurred as we progressed through the first half of the year's pandemic (January - June), we plotted the frequency of each theme along the 2020 timeline. For this, we combined Negative Continued Growth scenarios $(n=24)$ with Collapse scenarios $(n=78)$. The purpose was to present a categorisation that better represented the spirit of thematic content (i.e. generally positive versus generally negative), over time. Figure 4 plots the popularity of themes across the first half of 2020. Only one publication each was found from January and February. The Center for Strategic and International Studies held an interactive scenario workshop at the Global Security Forum in late 2019, and published their work at the start of the next year (Brannen, Haig, Schmidt, \& Hicks, 2020, January). The focus of their workshop was to develop scenarios that stress-tested assumptions about governance around global emerging technologies. One of their scenarios, Patient Zero, imagined a near future where the global population experienced a pandemic (p. 21)

[Scenario] "Patient Zero" envisioned a pandemic linked to a
humanmade pathogen, laying clear the potential consequences of a
rapidly expanding and weakly governed global bioeconomy... The
modified pathogen was a coronavirus like the one responsible for
sudden-acute respiratory syndrome (SARS) and Middle East
respiratory syndrome (MERS)...

The single February publication we located was from Drewry (2020) who produced three scenarios: Collapse, Disciplined, and Positive Continued Growth. The rate of scenario production did not continuously increase over time. There was a sharp incline in scenario production in March $(n=44)$, followed by equally intense efforts in April $(n=67)$, a decline in May $(n=27)$, followed by a rapid increase in June $(n=67)$ that more than doubled the previous month's efforts. Though the more negatively themed scenarios (Collapse + Negative Continued Growth) were popular at the start of the year, by early summer Disciplined scenarios (with "return to normal" narratives) started to become more prevalent alongside the negative themes. 
Figure 4. COVID-19 scenario themes over time

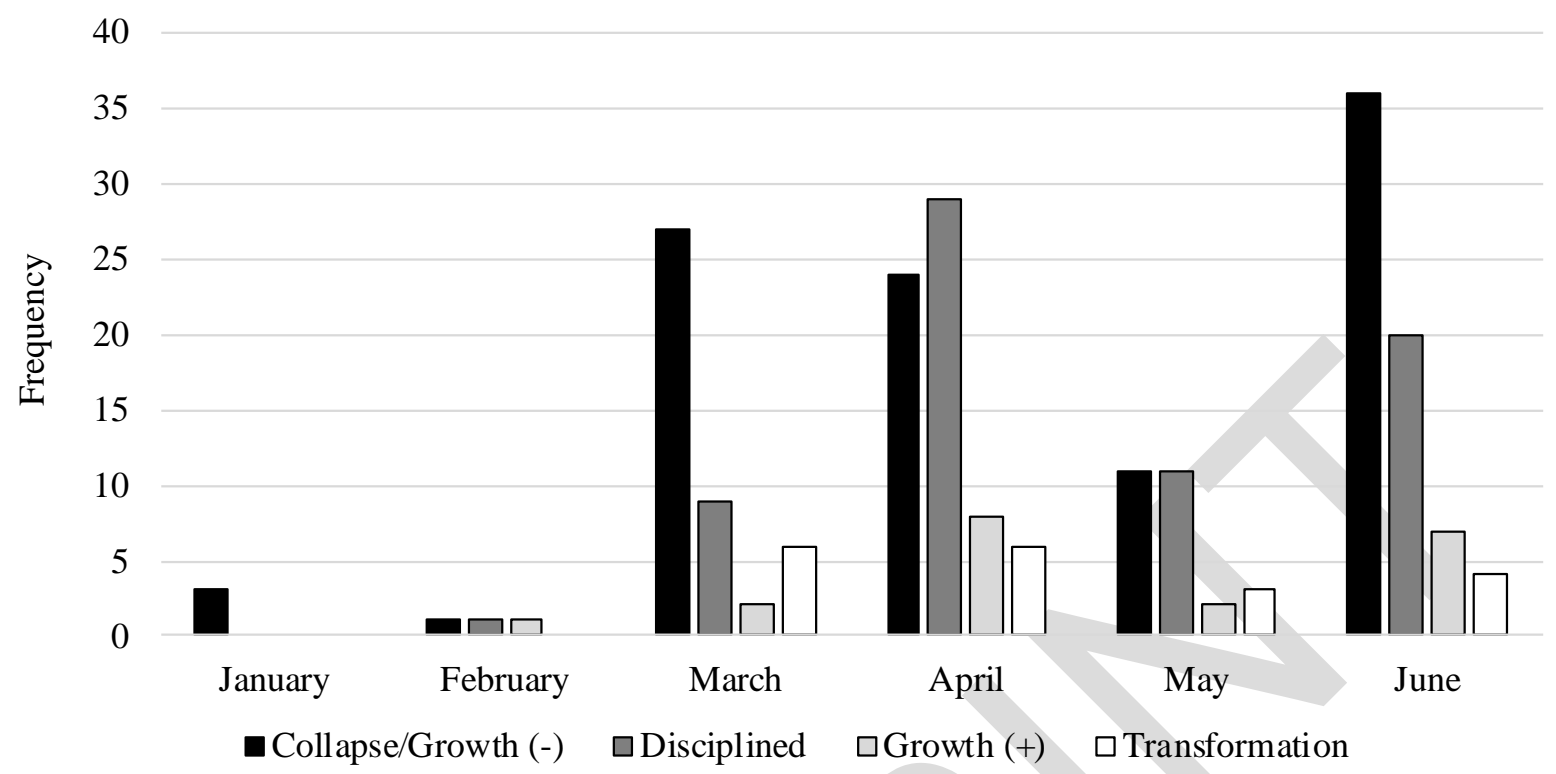

Note: Collapse and Negative Continued Growth (Growth (-)) scenarios are combined.

Interestingly, 20\% of Transformation scenarios with a specific focus on a world pandemic in 2020 were developed before 2020. In 2018, Small Wars Journal published, "SOF Futures: Pathways Through the Transition", that reported five scenarios about plausible futures for special operations forces (Cederquist, Gibbon, \& Lum, 2018, September). Various scenarios discuss biological threats, from sudden breakthroughs in synthetic biology and bio(industrialism) resulting in "a dazzling array of amazing and dangerous creations," that spread across the globe, to a redevelopment of ISIS that brings on fresh biological global threats where "the rest of the world seems to descend into more of the same chaos."

The final characteristic that addresses Cairns \& Wright's (2020) second proposition looks at the number of scenarios developed from each team of practitioners. Between the months of January and June, practitioners developed a range of 1 - 48 COVID-19 focused scenarios. EIU produced the largest number of scenarios in a single publication. Regardless if we adjust to the publication level or organisation level as the source for each scenario group, the Mode reflects the industry standard of three scenarios per publication.

\section{Proposition 3: General audiences}

The final set of analyses looks at how the scenario content was created and how this translated to the kind of information and data that populated the narratives. As well, we analysed whether members of the target audiences for the scenarios were included in scenario development process at any stage.

Figure 5 compares the preferences for the kind of information that populated each scenario (qualitative narratives, quantitative probabilities, or a mixture of both), based on the method 
of data collection used to develop the scenarios (desk research, participatory group work, or a blended method of both). An equal percentage of scenarios were developed through more solitary desk research methods and a blending of desk research with partial participatory group work (45.8\% respectively). A small minority of scenarios were developed solely from interactive participatory groups $(8.3 \%)$. Regardless of which method of development was used, qualitative narratives were significantly favoured for scenario narratives $(62 \%), \chi^{2}(4, n$ $=216)=42.31, p<.000$. Taking into consideration scenario content that included both qualitative and quantitative information, we find that the vast majority of scenarios $(86.1 \%)$ included qualitative narratives to help illustrate plausible futures, whether these futures were a continuing active pandemic or emergence from the pandemic. Practitioners who engaged in purely (or almost entirely) desk research to gather evidence for their scenarios produced nearly all of the quantitative COVID-19 scenarios. Quantitative scenarios were centred around modelling different infection and mortality rates with incubation time (Kissler, Tedijanto, Goldstein, Grad, \& Lipsitch, 2020, April), disease and symptom severity (Lavoix, 2020, May), and economic outcomes (Verbraken \& Sampieri, 2020).

\section{Figure 5. Scenario data by method of information/data collection}

Desk research

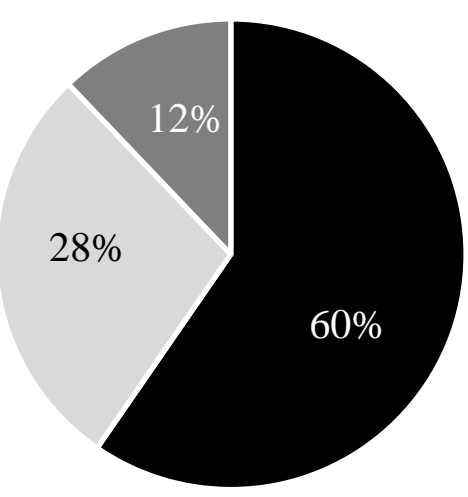

Blended

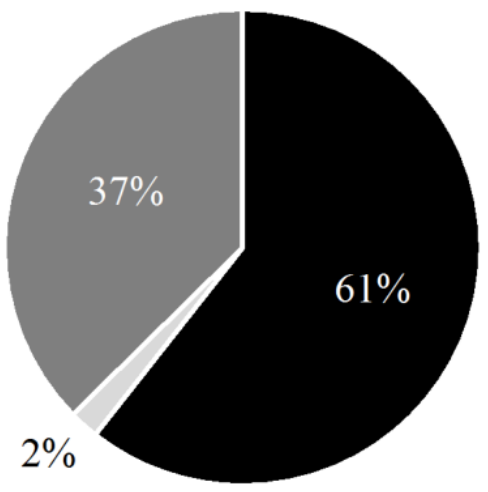

Participatory

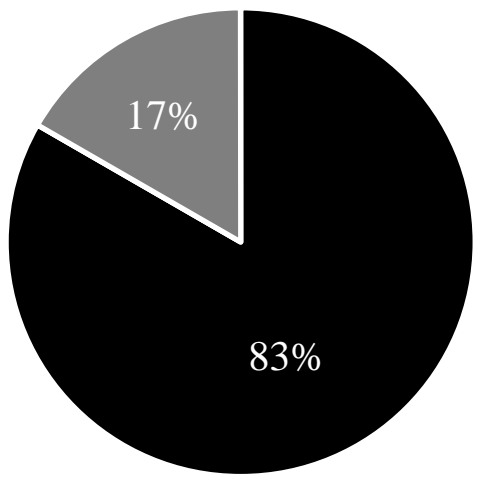

- Qualitative $=$ Quantitative $\quad$ Mixture

Our final analysis focuses on the level of scenario engagement by the affected decision makers. Out of 216 COVID-19 related scenarios, only 25 scenarios from five publications involved industry decision makers at some point in the process. At the collaborative level, three scenarios were developed by Drewry (2020) maritime consulting firm after consulting with Chinese port operators for the container shipping industry. The four other publications were the products of consulting firms, scenario experts, and industry executives working together. The Advisory Board healthcare consulting firm, members of the larger US health system, and internal healthcare experts developed 12 scenarios for US hospital preparedness (Kuchta, Lazerow, Pratt, \& Tyrell, 2020, March). Members of the University of Minnesota's Board of Regents developed three scenarios in conjunction with scenario consultants in 
preparation for the 2020/21 academic year (Ikramuddin, 2020, May). The Minnesota Department of Health (2020, June) developed three scenarios with education experts for public and private schools (pre-K through $12^{\text {th }}$ grade) in preparation for the 2020/21 academic year. Scenario experts from the University of Strathclyde, together with members of the Glasgow Chamber of Commerce, developed four scenarios for the greater Glasgow city region (McKiernan, Wright, Thomson, \& Gupta, 2020, July). One dimension the 25 scenarios share across the two categories of engagement with the decision makers (i.e. collaboration with decision makers within the scenario development process and consultation/collaboration with decision makers outwith the scenario development process) is that all these scenarios contain highly specific content directed at a single industry or organisation.

\section{Limitations}

Our dataset could reflect some potential biases from our selection process. First, we accessed largely English-language primary COVID-19 scenarios. As such, our dataset may reflect our bias towards accessing only English-language COVID-19 scenarios, or it may be an accurate reflection of the corpus of COVID-19 scenarios available at the time. Firms, organisations, researchers, practitioners, and media that published their COVID-19 scenarios in other languages - reflecting any number of social, cultural, economic, and political differences may compare differently on Cairns \& Wright's (2020) three main propositions. Clearly, it is important to acknowledge that our attempt to evaluate these authors' propositions is through the lens of mostly western, English-speaking practitioners, although, as we have documented, the focus of the scenarios included governments, organisations, and populations across the world.

The second limitation is that the majority of our dataset is populated with scenarios that were developed at arm's length by external consultants. It may be the case that consulting firms were more likely to openly publish their COVID-19 scenarios than other organisations - in an attempt to generate business rather than make, perhaps secretive, strategic decisions. However, it may also be the case that these consulting firms were, in fact, the main producers of all COVID-19 scenarios. To recall, our dataset was built from various internet searches, as well by directly contacting organisations and executives across several platforms, requesting their willingness to share any COVID-19 scenarios their organisation developed. From this multi-front approach, we were able to collect COVID-19 scenarios that were not publicly available at the time. It remains the case, though, that we are unable to assess what we did not receive (or even whether there was any further content to receive) in order to gain a clearer picture of the potential for bias in our dataset and subsequent analyses.

\section{Discussion}

Our investigation provides an evaluation of Cairns \& Wright's (2020) three main propositions about COVID-19 scenarios, using the framework of a comprehensive typology that covers process, content, and implementation phases of scenario planning. Recall that these authors' propositions are that the mass-produced COVID-19 scenarios reflect frozen 
pictures of the practitioners' temporally-bound knowledge, take a global perspective and fail to incorporate information that is valuable to their intended audiences, and that their mode of communication/delivery is intended for a general audience, failing to either engage or address the subtleties and action potential of affected communities. The aims of the paper were to evaluate the potential value of these scenarios for their intended audiences and provide guidance for future scenario planning in times of great disruption - by addressing both process and content issues.

Our analyses largely support Cairns \& Wright's (2020) initial propositions regarding the 216 COVID-19 scenarios produced in the months January to June, 2020, plus the bonus five scenarios published 18 months earlier. Together, our papers develop and reinforce the message that scenario audiences and scenario practitioners should make an evaluation of extant and to-be-developed scenario sets using yardsticks of (i) quality process and (ii) quality content.

\section{Scenario development process}

In terms of the scenario development process, high quality scenario planning will include affected community participation from the start. The act of involving stakeholders ensures their voices, concerns, insights, and opinions are integrated into a shared thinking process. An example of this was found in the Drewry (2020) scenario development, which involved consulting with Chinese port operators at the start of the scenario planning. This co-creation activity resulted in a variety of scenarios (optimistic, medium, and worst cast), but collectively the scenarios "exposed the fragility of global supply chains that are overly dependent on a single manufacturing source," and provided shipping companies a space against which to test their policies and practices, "carriers would be forced to revisit the playbook from the financial crash of a decade before... shippers will look to broaden their sourcing options as a form of insurance".

A low-quality process is typified by the absence of stakeholder voices and is often a result of largely isolated, practitioner-based, desk research. As a consequence, the resultant scenario content is ambiguous on the issues that concern the readers of the scenarios. Our analyses reveal that the majority of early COVID-19 scenarios were developed exclusively at arm's length by independent consultants using largely desk-based research to gather information and develop scenarios. Examples of low-quality process were found in the EIU (2020) scenarios. Table 3 presents a comparative ranking of the 10 most popular verbal expressions, or terms, contained within the EIU scenarios against the most popular terms contained within the scenarios developed with stakeholder participation, based on weighted percentages. ${ }^{2}$ The summary table helps illustrate how the more common, generalised EIU scenario terms lack spotlight and offer a diffuse illumination of key issues, compared to the concentrated focus of stakeholder-participation development of scenarios. EIU made several references to general

\footnotetext{
${ }^{2}$ NVivo software was used for text analysis. Results reflect weighted percentages of words and their stems, after standard stock words were removed (QSR International Pty Ltd., 2020). By default, NVivo adjusts all words to lower-case for analysis.
} 
geographic territories (e.g. global, regions, and countries), whereas the stakeholder-focused scenarios referenced more specific territories (e.g. China, Glasgow city, Minnesota, port, school, and university). There were no focused references to stakeholders in EIU's scenarios, yet those scenarios developed with stakeholder participation at any point in scenario planning resulted in focused references to several stakeholder groups in the narratives (e.g., patients, staff, and students). Note, especially, the verbal expressions, or terms, common in the stakeholder-focused scenarios deal with stakeholder issues and so are likely to prompt consideration of actions by those affected stakeholders (cf Cairns \& Wright, 2020). In short, it is important to ensure stakeholders and decision-makers are included in any scenario development process because, amongst other things, participation enables those in the process to gain the greatest insights from the intervention (Crawford, 2019). This practice helps "forge new common vocabulary and a rethink of the units of analysis" (Wilkinson, 2009, p. 108). Wack (1985) argues that scenario development, by its very process, should be transformative and so a necessary step in maximising the value of scenario planning. By engaging in participative scenario planning, decision-makers go through the process of what Wack calls "re-perceiving". That is, questioning their assumptions about the workings of the business environment, leading decision-makers to change and reorganize their mental models of reality, which increases the desired outcome of articulated action (Cairns, Wright, \& Fairbrother, 2016; Cairns, Wright, Fairbrother, \& Phillips, 2017).

Table 4. Most frequent words by scenario

\begin{tabular}{llllll} 
EIU & Drewry & $\begin{array}{l}\text { Advisory } \\
\text { Board }\end{array}$ & $\begin{array}{l}\text { Minnesota } \\
\text { Department of } \\
\text { Health }\end{array}$ & $\begin{array}{l}\text { Glasgow } \\
\text { Chamber of } \\
\text { Commerce }\end{array}$ & $\begin{array}{l}\text { University of } \\
\text { Minnesota }\end{array}$ \\
\hline countries & container & advisory & school & impact & university \\
global & shipping & care & students & pandemic & case \\
economy & port & health & covid & city & covid \\
oil & covid19 & board & health & economy & students \\
prices & outlook & supplies & staff & levels & best \\
virus & global & staff & use & glasgow & moderate \\
regions & china & capacity & face & many & response \\
expect & virus & virus & guidance & pulse & worst \\
fiscal & carrier & member & distancing & sector & daily \\
remain & impact & patients & people & investments & minnesota \\
\hline
\end{tabular}

Note: EIU scenarios were largely developed through non-participative methods while the other five groups integrated stakeholder participation into their process (Drewry Shipping Consultants Limited, 2020; Ikramuddin, 2020, May; Kuchta, Lazerow, Pratt, \& Tyrell, 2020, March; McKiernan, Wright, Thomson, \& Gupta, 2020, July; Minnesota Department of Health, 2020, June; The Economist Intelligence Unit, 2020)

High quality scenario planning employs a structured process. Chermack identifies 10 schools of scenario planning. Most are modifications of three main models. Each model is developed along several distinct stages that strategically guide practitioners through the scenario 
development process. The Intuitive Logics model is a plausibility-based model that relies on group participation as a method of exchanging ideas and challenging initial assumptions. The major inputs are qualitative and are comprised of a group's subjective interpretations of the core problem(s). The outcomes are a selection of complex scenarios that represent a variety of socially constructed, plausible realities, absent of judgments on likelihood (Cairns \& Wright, 2018). The Intuitive Logics model has been reported to be the prevailing model of scenario planning (Wack, 1985; Bradfield, Wright, Burt, \& Van der Heijden, 2005; Ringland, 1998). The Probabilistic Modified Trends model encompass Cross-Impact Analysis and Trend-Impact Analysis methods (Gordon, Cross-impact method, 1994a; 1994b). These latter methods are probability based. They perform multi-stage, model-based modifications that account for practitioners' expectations about the future, therefore, are largely normative in development. Both methods take a computer-assisted interactive approach to communication and decision-making. Information is generated from desk research and group participation, relying heavily on quantitative input and output. The French model, La Prospective, incorporates features of the Intuitive Logics model, but is more elaborate, complex and more mechanistic, relying on computer-based modelling with roots in Probabilistic Modified Trends (Godet \& Roubelat, 1996). It is more preference-based than the other models, however, scenarios that appear to break mental maps or indicate new possible directions are prioritised, giving a mix of normative and descriptive elements, relying heavily on quantitative data.

By contrast, most of the information provided by the organisations who published COVID-19 scenarios does not reveal whether practitioners used a structured method for developing their scenarios. However, we can infer some knowledge about particular development processes from the information available in the reports that accompany the scenario presentations. Our analyses reveal that the majority of scenarios contained primarily qualitative information and the majority of these included participatory methods, though we cannot know how extensive participation was, nor how large the groups were, particularly with the blended methods (desk research and participatory). Of the purely participatory/qualitative scenarios, the majority of these are highly complex and elaborative, reflecting similar inputs and outcomes to the Intuitive Logics model. The University of Strathclyde facilitators who worked closely with the Glasgow Chamber of Commerce were the one group who provided us with their process information, which followed the Intuitive Logics model. The team identified numerous driving forces, developed seven clusters, ranked each cluster by their level of assumed impact and predictability, identified the two most critical cluster uncertainties, populated their narratives, titled them, and developed four scenarios.

Low quality scenario planning does not utilize a structured and defensible process and resembles more of a "brain dump" in underpinning effort. Particularly when working with statistical forecasting models, parameters can be easily adjusted to give a quick selection of outcomes, without the need for justification. These kinds of scenarios are often less complex with little qualitative elaboration. Examples of low-quality output can be found in the four scenarios developed by two consultants at MSCI Inc. They used MSCI's macroeconomic model with IMF's four GDP scenarios (V-shaped, U- shaped, L- shaped, and Swoosh- 
shaped) to project basic financial projections of market impact, growth shocks, and equity performance over a forthcoming 10 years. All these scenarios projected an initial drop and an eventual rise, revealing a highly normative narrative, reflecting more what investors hope, rather than challenging their initial mental models.

The final process sub-section is the quantity of scenarios developed from a single workshop or intervention. The best-case outcome is more than two (Wack, 1985; Schoemaker, 1993; Van der Heijden, 1997). Particularly, there should be enough scenarios to challenge mental models, test policy, and inform future decisions. Bunn and Salo (1993) suggest several scenarios may be needed to test for robustness and flexibility of a strategic plan or policy, before a satisfactory analysis can be achieved. The majority of COVID-19 scenarios produced in a single publication were more than two, spanning a selection of themes. An example of several scenarios developed to provide conditions for testing decisions and policies is Inside Higher Ed's April publication of 15 scenarios for US colleges and universities to consider for the fall semester (Maloney \& Kim, 2020, April). They fall along a continuum of "back to normal on one end and fully remote learning on the other".

\section{Scenario content}

In terms of scenario content, the worst-case outcome for quality is the development of a single scenario. Crawford (2019, p. 17) states, "A single scenario offers highly limited parameters and no comparisons to other future realities with which to challenge mental models and alternative options." An example of this is comes from Vision Foresight Strategy LLC (2020, April), with their publication, Preparing for the Bad Scenario. They developed the scenario without stakeholder involvement and offered only three dimensions of focus: two statements addressed restrictions, one statement addressed a lack of peak infection rates, and the final statement addressed a recession. They acknowledge, "This scenario, which is admittedly simple, does not take into account other potentially critical changes external to the US, such as outcomes in Europe, economic and political relations with China, and other possible second and third order effects of the initial pandemic." It is difficult to determine how their intended audiences - government and business leaders, conflict and security professionals, non-profit and community leaders, education leaders and professions, and parents and families - are to find meaningful value in a scenario that touches upon only three dimensions presented in four brief statements.

From a content view, high quality scenarios will include narratives with targeted messages/implications that are specific to affected communities. "Specific" should not be taken to imply a completely narrow community focus, but, rather, this focus should be informed by overlapping perspectives, whether it be global with a regional perspective, or national with a community/local perspective. If practitioners clarify their scenario development goals and anticipate features of the depicted scenario impacting on affected communities, they have a better chance of increasing the success of their scenario planning efforts. Low-quality scenarios default to simple global perspectives. They paint the future with broad strokes and are developed with a general use in mind. 
A second content sub-category is the complexity of each scenario. We have already touched upon this topic in previous discussions, but feel it requires a mention of its own. High quality scenarios will present and incorporate a variety of driving forces, predetermineds, and powerful stakeholder actions (e.g., actions/reactions from governments and citizens to unfolding events in the contextual environment). Low quality scenarios will feature one to two main drivers and little elaboration. Such scenarios may also only provide a simple qualitative narrative or a handful of quantitative projections. To recap, our analyses show that $69.4 \%$ of COVID-19 scenarios produced between January and June 2020, and five pandemicrelated scenarios produced in 2018 , met our criteria for low complexity - with scenarios expressed in a short word-length.

An example of high-quality scenario perspectives and complexity came from the Minnesota Department of Health, developed for pre-kindergarten through grade 12 schools in the state. They discussed local, regional, or state-wide COVID-19 metrics, social distancing and exposure, capacity limits, distance learning, face coverings and shields, vulnerable populations, hygiene practices, cleaning materials, monitoring and excluding for illness, suspected or confirmed positive cases, water and ventilation systems, transportation, and mental health and wellness. They also provided quantitative data complimented by rich qualitative narratives.

By contrast, an example of low-quality scenario perspectives and complexity was provided by a member of the Brussels-based, not-for-profit think-tank, Friends of Europe. Three scenarios were developed mid-March and were presented with the qualifier, "What follows is neither comprehensive nor science-based." They were short narratives $\left(M_{\text {words }}=194.67\right.$, $\left.S D_{\text {words }}=68.38\right)$ that discussed global and national identities and largely addressed political governance, but it remains unclear whom their intended audience was supposed to be.

Furthermore, the scenario narratives appeared to reflect the reality we knew in March 2020, and did not provide an exploration of different plausible futures to challenge mental models (e.g., assumptions were made about significant uncertainties: "Brexit talks resume but with no sense of urgency" and "It's not idealistic to expect international cooperation in times of crisis. It has been done [during the 2008-2009 financial crisis]").

Another measure of scenario quality focuses on whether the actions of the powerful were depicted in the storylines (e.g., by governments and by citizens). High quality content will include some form of modelling of the self-interested actions of powerful stakeholders. Low quality content will be devoid of these types of details. An example of high-quality, reflective scenario content was found in the 2020 Global Security Forum, Patient Zero (Brannen, Haig, Schmidt, \& Hicks, 2020, January). The scenarios were developed for national security and technologies governance audiences. Here, the Patient Zero scenario features specific actions and plausible causal chains of events for members of these industries. To illustrate:

A modified pathogen from a European bioresearch lab has caused a global pandemic... The modified pathogen was a coronavirus like the 
one responsible for [SARS and MERS]... The incident further raises concerns of laboratory biosecurity and biosafety, which have been significantly underinvested in... claimed by multiple terrorist groups... following an inquiry by U.S. health agencies and the intelligence community, the surgeon general of the United States announced that none of these groups possess the skill and access to materials necessary... The person of interest was infected with the strain either unintentionally or in an attempt to or in the course of infecting others at the Tegel Airport. He boarded a flight... to New York... Global drug manufacturers working in collaboration with national biodefense researchers in countries around the globe are surging to develop a treatment and vaccine, but they are months away from a workable trial. (pp. 21-22)

An example of low-quality content, absent of stakeholder modelling was found within the single-practitioner developed scenarios at Multiverse Design (Zaidi, 2020, March). Here, four scenarios reflected each of Dator's (2009) generic archetypal themes, crossed with Zaidi's (2017) Seven Foundations model: political, economic, philosophical, environmental, scientific and technological, artistic, and social. Though the scenarios contain a fair amount of information, their narratives convey almost no stakeholder modelling, and instead use generalised language, e.g. "Policies that continue to benefit the wealthy" and "Anti-loneliness movement and services".

The final sub-category is the temporally-bound knowledge of practitioners which populates the scenario narratives. As discussed earlier, high quality scenarios will reflect an "ongoing refinement and adaptation of perspectives on the future" (Cairns \& Wright, 2020, p. 3). Particularly in times of great disruption, where information changes not just daily, but hourly, it is necessary for scenarios to reflect the quality of volatility of our unfolding reality, in order to bring value to their intended audiences. This is achieved by dynamic revisions to update scenario content or develop new scenarios that expand and develop existing ones. It is not that past scenarios should be forgotten and replaced, since their time-dated pictures of plausible futures always have the potential for aiding decision-making. However, their value is increased when the narratives are expanded, built on, and/or reanalysed as time passes and unexpected events unfold. Low quality scenarios remain time-dated frozen pictures that may reflect limited practitioner perspectives and outdated knowledge. Worse, scenarios may end up serving merely to reinforce existing knowledge and expectations (Molitor, 2009). Examples of higher quality efforts to improve scenario content came from the three groups that drafted new scenarios as time progressed: those produced by Deloitte and Kantar (Abraham, Burdett, Carbone, \& Warwick, 2020, April; Blau \& Schwartz, 2020, April; Kalish, et al., 2020, April; Kantar, 2020, June). Although many of these scenarios were, perhaps, overly simplistic and general, the practice of continual revision demonstrated the kind of effort necessary to ensure scenarios become more than just parlour game, to borrow Molitor's language. By contrast, examples of low quality, temporally-bound scenarios are prevalent in out 138 of our COVID scenarios. For example, IARAN LTD, produced three 
scenarios in June that included the following ambiguous and time-dated content, "Lower levels of hygiene among poorer members of society drive the spread of the virus" (IARAN, 2020, June, p. 3). The team from the Atlantic Council provided an equally limited perspective with statements like, "For the Europeans, it is the same old battle that was fought during the eurozone crisis," in their post-COVID-19 scenarios.

Finally, we emphasise that as we worked through our yardstick evaluations, we noted other ways in which scenario sets could be distinguished, e.g. by themes, short verses long time horizons, etc. On these additional points of difference, a yardstick evaluation of quality is not possible. However, these and other points of difference remain important aspects of both the process and content of the developed scenarios. To help illustrate the level of importance other profiled features can serve, we briefly revisit the division of themes presented in Figure 4. Recall that the popularity of themes adjusted as we progressed through the first six months of the pandemic. Within the first month, Collapse-themed scenarios were the most common plausible futures created by practitioners for their intended audiences. One month later, as the pandemic spread towards western countries, scenarios started to reflect more Disciplined futures. Even Positive Growth futures started to gain a bit in popularity. The first question to ask is, why the sudden shift? If, for example, more practitioners were aiming to reflect a better balanced or varied view of plausible futures through the pandemic, then we should expect to see a closer spread in frequencies across the themes by April. The data, however, do not reflect this, not for April, nor for any of the later months. The surge in Disciplined scenarios may have been a reflection of bias in scenario thinking, particularly, wishful thinking. Recall that Table 3 offers examples of the kinds of normative and desirable passages within Disciplined and Positive Growth scenarios. March 2020 was our pivot into a fast-moving global disruption. The shock of finding ourselves forced to navigate an unexpected $^{3}$ new reality, with almost paradigmatic shifts in the making (e.g., new language, challenged social constructs, shifting economics, and emerging technologies) may have created a backlash effect in many practitioners' scenario thinking, biasing them towards a more familiar mode of envisioning our shared futures, and as a consequence, reflecting their desires to return to what they know and, importantly, what their clients know. The potential for bias in scenario thinking is further supported by the low levels of Transformation-themed scenarios. In a time of great disruption and forced transformations in industries, economies, supply chains, and even human interaction, it is, in our view, an oversight that practitioners did not explore plausible transformative - and even Wild Card - futures.

If such a bias in scenario thinking existed for some practitioners, then this reflects a potential failure in scenario planning. Arguably, the main purpose of effective scenario planning is to engage with an audience (practitioners, organisations, decision-makers, and stakeholders) in

\footnotetext{
${ }^{3}$ It is important to note that though a common theme in 2020's narrative was to frame the COVID-19 pandemic as a black-swan, unforeseeable, or unexpected, this was our $10^{\text {th }}$ pandemic since 1918 , and $6^{\text {th }}$ within the $21^{\text {st }}$ century, where the majority have been caused by a novel coronavirus (World Health Organization, 2020). The WHO, CDC, CSIS, and other organisations, whose purpose is to regularly consider biological threats to our planet, have existing pre-2020 publications discussing the continued potential for new pandemics, including in the year 2020.
} 
order to challenge their mental models, aid them in "re-perceiving" their environment, the rules of the game, and their role as actors - in order to aid development of effective strategies and build resilience as the future unfolds. Employing normative thinking by, simply, representing positive aspect the past and them calling it the "future" is, in our view, the antithesis of effective scenario planning. Furthermore, we question why any organisation or government would want to return to a past reality that, at least in part, initiated the causal chain of events that brought on not only the COVID-19 pandemic but the five preceding pandemics of the last 20 years?

\section{Conclusion}

Our analyses reveal that Cairns \& Wright's (2020) initial propositions about the value in quickly produced COVID-19 scenarios were well-founded. Our repository of scenarios produced within the first 6 months of 2020 largely reflect low-quality process (little stakeholder involvement, few revisions, low quantity output, and a lack of transparency on scenario development methodologies employed) and low-quality content (largely global perspectives with general applications, low complexity, questionable levels of stakeholder modelling, and scenario content that is frozen in time).

\section{Works Cited}

Bezold, C. (2010). Lessons from using scenarios for strategic foresight. Technological Forecasting and Social Change, 77(9), 1513-1518. doi: 10.1016/j.techfore.2010.06.012.

Bradfield, R., Wright, G., Burt, G., \& Van der Heijden, K. (2005). The origins and evolution of scenario techniques in long range business planning. Futures, 37(8), 795-812. doi: 0.1016/j.futures.2005.01.003.

Bunn, D. W., \& Salo, A. A. (1993). Forecasting with scenarios. European Journal of Operational Research, 68, 291-303. doi: 10.1016/0377-2217(93)90186-Q.

Cairns, G., \& Wright, G. (2018). Scenario Thinking (2nd ed.). Switzerland: Palrave Macmillan.

Cairns, G., \& Wright, G. (2020). A reflection on the mass production of scenarios in response to COVID-19. Futures \& Foresight Science, 2, 1-5. doi: 10.1002/ffo2.34.

Cairns, G., Wright, G., Fairbrother, P. and Phillips, R., 2017. 'Branching scenarios' seeking articulated action for regional regeneration-a case study of limited success. Technological Forecasting and Social Change, 124, pp. 189-202. doi: 10.1016/j.techfore.2017.01.014

Cairns, G., Wright, G. and Fairbrother, P., 2016. Promoting articulated action from diverse stakeholders in response to public policy scenarios: a case analysis of the use of 'scenario improvisation'method. Technological Forecasting and Social Change, 103, pp. 97-108. doi: 10.1016/j.techfore.2015.10.009

Crawford, M. M. (2019). The comprehensive scenario intervention typology. Technological Forecasting and Social Change, 149, 119748. doi: 10.1016/j.techfore.2019.119748. 
Dator, J. (2009). Alternative futures at the manoe school. Journal of Futures Studies, 14(2), $1-18$.

Ducot, G., \& Lubben, G. J. (1980). A typology for scenarios. Futures, 12(1), 51-57. doi: 10.1016/S0016-3287(80)80007-3.

Fergnani, A., \& Jackson, M. (2019). Extracting scenario archetypes: A quantitative text analysis of documents about the future. Futures \& Foresight Science, 1(2), 1-14. doi: 10.1002/ffo2.17.

Glenn, J. C., \& Gordon, T. J. (2000). Millennium 3000 scenarios. In State of the Future at the Millennium.

Godet, M., \& Roubelat, F. (1996). Creating the future: The use and misuse of scenarios. Long Range Planning, 29, 164-171. doi: 10.1016/0024-6301(96)00004-0.

Gordon, T. J. (1994a). Cross-impact method. American Council for the United Nations University.

Gordon, T. J. (1994b). Trend impact analysis. In J. C. Glenn, \& T. J. Gordon (Eds.), Futures Research Methodology: The Millennium Project (2 ed.).

Grimmer, J., \& Stewart, B. (2013). Text as data: The promise and pitfalls of automatic content analysis methods for political texts. Political Analysis, 21(3), 267-297. doi:10.1093/pan/mps028.

Heugens, P. P., \& van Oosterhout, J. (2001). To boldly go where no man has gone before: Integrating cognitive and physical features in scenario studies. Futures, 33, 861-872. doi: 10.1016/S0016-3287(01)00023-4.

Huss, W. R., \& Honton, E. J. (1987). Scenario planning-What style should you use? Long Range Planning, 20(4), 21-29. doi: 10.1016/0024-6301(87)90152-X.

Inayatullah, S. (2009). Questioning scenarios. Journal of Futures Studies, 13(3), 75-80. Retrieved from https://jfsdigital.org/articles-and-essays/2009-2/vol-13-no-3february/scenario-symposium/questioning-scenarios/.

Millett, S. M. (2003). The future of scenarios: challenges and opportunities. Strategy \& Leadership, 31(2), 16-24. doi: 10.1108/10878570310698089.

Molitor, G. T. (2009). Scenarios: Worth the effort? Journal of Futures Studies, 13(3), 81-92. Retrieved from https://jfsdigital.org/wp-content/uploads/2014/01/133-S02.pdf.

QSR International Pty Ltd. (2020). NVivo (released in March 2020). Retrieved from https://www.qsrinternational.com/nvivo-qualitative-data-analysis-software/home.

Ringland, G. (1998). Scenario Planning: Managing for the Future. Chichester: Wiley.

Schoemaker, P. J. (1993). Multiple scenario development: Its conceptual and behavioral foundation. Strategic Management Journal, 14, 193-213.

Spaniol, M. J., \& Rowland, N. J. (2018). Defining scenario. Futures \& Foresight Science, 1(1), 1-13. doi: 10.1002/ffo2.3.

Van der Heijden, K. (1997). Scenarios: The Art of Strategic Conversation. New York: John Wiley.

Van der Heijden, K., Bradfield, R., Burt, G., Cairns, G., \& Wright, G. (2002). The Sixth Sense: Accelerating Organizational Learning with Scenarios. West Sussex: John Wiley \& Sons.

Wack, P. (1985). Scenarios: Shooting the rapids. Harvard Business Review, 139-150.

Wayback Machine. (1996, May 12). Retrieved from Internet Archive: https://archive.org/ 
Wilkinson, A. (2009). Scenarios practices: In search of theory. Journal of Futures Studies, 13(3), 107-114.

World Health Organization. (2020). Coronavirus disease 2019 (COVID-19): Situation report, 30. Retrieved from https://apps.who.int/iris/handle/10665/331119: World Health Organization (WHO).

Zaidi, L. (2017). Building Brave New Worlds: Science Fiction and Transition Design. Toronto, Ontario: OCAD University.

\section{Scenario References}

Abraham, D., Burdett, L., Carbone, C., \& Warwick, C. (2020, April). Anticipating the Balance of 2020: Global Scenarios Exploring COVID-19. New York, NY: Retrieved from https://sites.kantarconsulting.com.

acaps. (2020, April). COVID-19: Scenarios. ACAPS. Retrieved from https://www.acaps.org/. Barnakova, Y., Skoritowski, E., \& Snyder, S. (2020, April). COVID-19 and the Future of Work: Four Scenarios. Heidrick \& Struggles International, Inc. Retrieved from https://www.heidrick.com/KnowledgeCenter/Publication/COVID19_and_the_future_of_work_Four_scenarios.

Begley, S. (2020, May). Three potential futures for Covid-19: recurring small outbreaks, a monster wave, or a persistent crisis. STAT, Retrieved from https://www.statnews.com/2020/05/01/three-potential-futures-for-covid-19/.

Blau, A., \& Schwartz, P. (2020, April). The World Remade by COVID-19: Scenarios for Resilient Leaders. Deloitte Development LLC. Retrieved from https://www2.deloitte.com/global/en/pages/about-deloitte/articles/covid-19/covid-19scenarios-and-impacts-for-business-and-society-world-remade.html.

Brannen, S. J., Haig, C. S., Schmidt, K., \& Hicks, K. H. (2020, January). Twin Pillars: Upholding National Security and National Innovation in Emerging Technologies Governance. Center for Strategic \& International Studies (CSIS). Retrieved from.

Burrows, M., \& Engelke, P. (2020, April). What world post-COVID-19? Scowcroft Center for Strategy and Security. Atlantic Council. Retrieved from https://www.AtlanticCouncil.org.

Candelon, F., De Villiers, P., Reichert, T., Lang, N., Di Carlo, R. C., \& Kchia, A. (2020, April). How Scenarios Can Help Companies Win the COVID-19 Battle. Boston Consulting Group. Retrieved from https://www.bcg.com.

CDC. (2020, April). COVID-19 Pandemic Planning Scenarios. Office of the Assistant Secretary for Preparedness and Response (ASPR). Retrieved from https://www.cdc.gov/coronavirus/2019-ncov.

Cederquist, J., Gibbon, A., \& Lum, R. (2018, September). SOF Futures: Pathways through the transition. Small Wars Journal, Retrieved from https://smallwarsjournal.com/jrnl/art/sof-futures-pathways-through-transition. 
Cooper, R. (2020, June). The worst-case scenarios for COVID-19 are still in play. pp.

Retrieved from https://theweek.com/articles/920046/worstcase-scenarios-covid19-arestill-play.

Crooks, E., Martin, P., Thompson, G., Flowers, S., Mielke, E., Hittle, A. L., . . Manghani, R. (2020, May). The world after Covid-19. Edinburgh: Wood Mackenzie. Retrieved from https://www.woodmac.com.

Drewry Shipping Consultants Limited. (2020, February 28). Container shipping outlook buttugly in 2 out of 3 COVID19 scenarios . PortandTerminal.com, pp. Retrieved from https://www.portandterminal.com/container-shipping-outlook-butt-ugly-in-2-out-of3-covid19-scenarios-drewry.

Forrest, N., Gillham, J., Kupelian, B., Tuckett, A., Lee, E., \& Teow, J. (2020, June). COVID19 UK economic update. PricewaterhouseCoopers LLP. Retrieved from https://pwc.co.uk/economics.

Forrest, N., Hawksworth, J., Kupelian, B., Tuckett, A., Lee, E., \& Teow, J. (2020, May). COVID-19 UK economic update. PricewaterhouseCoopers LLP. Retrieved from https://pwc.co.uk/economics.

Gattiker, C. (2020, March). Covid-19 - a scenario approach. Retrieved from Julius Bär: https://www.juliusbaer.com/de/insights/markets-explained/covid-19-a-scenarioapproach/

Green, M. J. (2020, March). Geopolitical Scenarios for Asia after COVID-19. Center for Strategic and International Studies. Retrieved from csis.org/analysis/geopoliticalscenarios-asia-after-covid-19.

Honey, G. (2020, April). What will a post virus world look like? Journal of Futures Studies, Retrieved from https://jfsdigital.org/2020/04/08/what-will-a-post-virus-world-looklike.

IARAN. (2020, June). COVID 19 Preliminary Scenarios for the Humanitarian Ecosystem. IARAN Ltd. Retrieved from https://www.iaran.org/.

Ikramuddin, H. (2020, May). The University's best, moderate and worst case COVID-19 response scenarios. The Minnesota Daily, pp. Retrieved from https://mndaily.com/article/2020/05/best-moderate-and-worst-case-covid-19response.

Islam, S. (2020, March). Three scenarios for a Covid-19 world: We can still make the right choices. Retrieved from Friends of Europe:

https://www.friendsofeurope.org/insights/three-scenarios-for-a-covid-19-world-wecan-still-make-the-right-choices

Kalish, I., Klein, M., Billa, G., Marquard, B., Blau, A., \& Willigman, P. (2020, April). Recovering from COVID-19: Economic Cases for Resilient Leaders. Deloitte Development LLC. Retrieved from https://www2.deloitte.com/global/en/pages/aboutdeloitte/articles/covid-19/covid-19-planning-scenarios-for-business-leaders-resilientworld-remade.html.

Kantar. (2020, June). Exploring COVID-19 future scenarios: US healthcare point of view. Washington, DC: Kantar. Retrieved from www.kantar.com/health. 
Kesson, K. (2020, April). Three scenarios for the future of education in the anthropocene. Journal of Futures Studies, Retrieved from https://jfsdigital.org/2020/04/12/threescenarios-for-the-future-of-education-in-the-anthropocene.

Kissler, S. M., Tedijanto, C., Goldstein, E., Grad, Y. H., \& Lipsitch, M. (2020, April). Projecting the transmission dynamics of SARS-CoV-2 through the postpandemic period. Science, 860-868. doi: 10.1126/science.abb5793originally.

Kuchta, S., Lazerow, R., Pratt, S., \& Tyrell, R. (2020, March). Coronavirus Scenario Planning: 12 Situations Hospital Leaders Should Prepare for. Washington DC: Advisory Board. Retrived from https://www.advisory.com/.

Lavoix, H. (2020, May). Worst Case Baseline Scenarios for the COVID-19 Pandemic. The Red (Team) Analysis Society. Retrieved from https://www.redanalysis.org.

Maloney, E. J., \& Kim, J. (2020, April). 15 Fall Scenarios. Inside Higher Ed. https://medicalfuturist.com/when-and-how-will-covid-19-end.

McKibbin, W. J., \& Fernando, R. (2020). The global macroeconomic impacts of COVID-19: Seven scenarios. CAMA Working Paper No. 19/2020, Retrieved at http://dx.doi.org/10.2139/ssrn.3547729.

McKinsey \& Company. (2020, May). COVID-19: Briefing Materials - Global Health and Crisis Response. McKinsey Crisis Response. McKinsey \& Company. Retrieved from https://www.mckinsey.com.

Mesko, B. (2020, April). When And How Will COVID-19 End? Retrieved from The Medical Futurist: https://medicalfuturist.com/when-and-how-will-covid-19-end

Minnesota Department of Health. (2020, June). 2020-2021 Planning Guide for Schools. Minnesota Department of Health. Retrieved from http://health.mn.gov.

MOODY'S. (2020, March). COVID-19: Gauging the Pandemic. Moody's Analytics. Retrieved from https://www.economy.com.

Moore, K. A., Lispsitch, M., Barry, J. M., \& Osterholm, M. T. (2020, April). COVID-19: The CIDRAP viewpoint. Minnesota: Center for Infectious Disease Research and Policy (CIDRAP). Retrieved from www.cidrap.umn.edu.

OECD. (2020, June). The World Economy on a Tightrope. OECD. Retrieved from www.oecd.org/economic-outlook/june-2020.

Palma, L. (2020, March). Two possible COVID-19 scenarios for employers in Mexico. Retrieved from JD Supra: https://www.jdsupra.com/legalnews/two-possible-covid-19scenarios-for-66007/

Roberts, S. (2020, May). This Is the Future of the Pandemic. The New York Times, p. Retrieved from https://nyti.ms/3dp17mY.

The Economist Intelligence Unit (EIU). (2020, June). EIU Global Forecasting Service. Retrieved from The Economist Group: http://www.eiu.com/

The Nielsen Company. (2020, May). Scenarios Beyond COVID-19: Rebound, Reboot, Reinvent. The Nielsen Company. Retrieved from https://www.nielsen.com/us/en/insights/article/2020/scenarios-beyond-covid-19rebound-reboot-reinvent.

Verbraken, T., \& Sampieri, J. (2020, May). Four COVID-19 Scenarios: What Might Happen Next? Retrieved from MSCI: https://www.msci.com/www/blog-posts/four-covid-19scenarios-what/01835985426 
Vision Foresight Strategy LLC. (2020, April). Roadmap for the Trans-COVID Period: An Update to our Foresight Roadmap for COVID Futures. Vision Foresight Strategy LLC. Retrieved from https://www.visionforesightstrategy.com/.

Vision Foresight Strategy LLC. (2020, March). Under the weather: A rapid forecast exploring the futures of global pandemics. Vision Foresight Strategy LLC. Retrieved from https://www.visionforesightstrategy.com/.

Wayback Machine. (1996, May 12). Retrieved from Internet Archive: https://archive.org/

World Health Organization. (2020). Coronavirus disease 2019 (COVID-19): Situation report, 30. Retrieved from https://apps.who.int/iris/handle/10665/331119: World Health Organization (WHO).

Zaidi, L. (2020, March). COVID-19: Reorganization scenarios. Multiverse Design. Retrieved from https://www.multiversedesign.com. 